\title{
Uso do território e impactos das construções de hidroelétricas na bacia do rio Araguari (Amapá-Brasil) ${ }^{1}$
}

\author{
Christian Nunes da Silva ${ }^{1}$, Ricardo Ângelo Pereira de Lima² e \\ João Marcio Palheta da Silva ${ }^{3}$
}

\footnotetext{
1 Pós-Doutorando em Desenvolvimento Regional no PPGMDR/UNIFAP, Doutor em Ecologia. Bolsista FAPEAP/CAPES. Professor Adjunto II da Universidade Federal do Pará. Docente do Programa de Pós-Graduação em Geografia (PPGEO/UFPA), Brasil. E-mail: cnsgeo@yahoo.com.br

2 Pós-Doutorando em Geografia no PPGEO/UFPA, Doutor em Geografia Humana. Bolsista FAPESPA/CAPES. Professor Associado II da Universidade Federal do Amapá, Brasil. E-mail: ricardoangelo_pereira@yahoo.es

3 Doutor em Geografia. Pesquisador em Produtividade do CNPQ. Professor Associado III da Universidade Federal do Pará, Brasil. E-mail: jmpalheta@ufpa.br
}

\begin{abstract}
RESUM 0: Discutir a gestão de políticas públicas e o uso dos recursos naturais implica identificar estes recursos, seu potencial e diversidade bem como considerar a racionalidade do processo de apropriação ao qual estes recursos estão submetidos, suas condições de acesso e controle por parte do Estado e da sociedade, em usos diferenciados do e no território. Neste sentido, este artigo propõe uma reflexão sobre o uso do território na Amazônia setentrional brasileira, por meio da implantação das Usinas Hidrelétricas (UHE) no rio Araguari, no estado do Amapá. Sem dúvida, a geração de energia é uma atividade necessária para a manutenção da qualidade de vida das populações, porém, monitorar e entender essas atividades é imprescindível para se evitar possíveis efeitos negativos de sua instalação e operação, tanto para o meio ambiente quanto para as populações atingidas direta e indiretamente pela instalação de grandes obras, como uma UHE.
\end{abstract}

Palavras-chave: Usina Hidroelétrica, Território, Recursos Naturais, Amapá.

\section{Territory use and impacts of hydroelectric construction in the watershed of river Ara- guari (Amapá-Brazil)}

\begin{abstract}
Discuss the management of public policies and the use of natural resources involves identifying these resources, their potential and diversity as well as consider the rationality of the appropriation process to which these resources are subject, their conditions of access and control by the state and society in the different uses of territory and in the territory. In this sense this article proposes a reflection on the use of land in the septentrional Brazilian Amazon, through the implantation of hydroelectric plants (HPP) on the river Araguari in the state of Amapa. Undoubtedly, the power generation is a necessary activity for maintaining the quality of life of the population, however, monitor and understand these activities is essential to avoid possible negative effects of their installation and operation, both for the environment and for the people affected directly and indirectly by the installation of large projects like a hydroelectric plant.
\end{abstract}

Keywords: Hydroelectric Plant. Territory. Natural Resources. Amapá.

\footnotetext{
${ }^{1}$ Trabalho oriundo dos debates realizados durante a execução do projeto "Novos ordenamentos territoriais na Amazônia: análises dos impactos gerados a partir da implantação de empreendimentos hidroelétricos no estado do Amapá", aprovado no Edital 02/2016, com recursos disponibilizados pela Fundação de Amparo à Pesquisa do Estado do Amapá (FAPEAP) e da Comissão de Aperfeiçoamento de Pessoal do Nível Superior (CAPES), coordenado pelo Prof. Dr. Christian Nunes da Silva.
} 


\section{INTRODUÇÃO}

Na maior parte da relação entre sociedade e natureza, o segundo elemento desta relação é visto somente como fornecedor de matérias-primas para o capital. Esta concepção perpassa toda a história das sociedades humanas, onde a utilização dos recursos naturais é vista como ilimitada e a ideia basilar está em tirar vantagem no uso destes recursos. Esse paradigma, defendido por diversos intelectuais, afirma que o capital deve transformar a matéria-prima natural em bens e produtos que são agregados à vida do homem, não levando em consideração o capital-natural ${ }^{2}$, preocupando-se em potencializar a produção de bens e serviços, de forma a "domesticar" a natureza, seja melhorando geneticamente os espécimes utilizados ou agregando mais tecnologia a fim de ofertar mais produtos ao mercado e, com isso, gerar mais lucro.

Entretanto, sem a devida utilização racional dos recursos naturais pela maior parte dos empreendedores, a sociedade se manifesta - de forma organizada - em movimentos sociais para impedir os ditos "problemas ambientais" causados pela utilização intensa dos recursos naturais, sem levar em consideração a finitude destes recursos. 0 agravamento desses problemas ambientais nas últimas décadas e a consequente mobilização de diversos segmentos populacionais, como é o caso dos movimentos ecológicos e/ ou ambientalistas (CASTELLS, 2001; SANTOS, 1994), é que caracterizam a crise socioambiental tão discutida no momento hodierno, e ao mesmo tempo indicam o esgotamento do estilo de economia e desenvolvimento predominantes, com o desenvolvimento/crescimento industrial crescente sem considerar 0 meio ambiente.

A necessidade de realizar esta pesquisa está em proporcionar mais informações sobre a influência dos empreendimentos hidroelétricos no estado do Amapá, mais especificamente nos municípios de Ferreira Gomes e Porto Grande - dois municípios contíguos, com graus diferenciados de impactos socioterritoriais decorrentes das atividades ligadas aos grandes projetos. Além do que, este trabalho vem propor o levantamento de informações sobre o uso dos recursos naturais e os impactos socioambientais causados por estes empreendimentos (EIA, 2013; PBA, 2013), visto que no estado do Amapá a atuação das grandes empresas causam impactos - sociais e ambientais - que alteram diretamente o modo de vida das populações que moram nas proximidades.

Estudos anteriores a este manuscrito já foram realizados em outras regiões brasileiras e demonstram que os riscos ambientais e sociais causados por empreendimentos hidroelétricos, desde sua construção até a operação, causam impactos significativos no contexto socioambiental onde estão inseridos (ROCHA, 2008). Todavia, em pesquisa de campo realizada no ano de 2015, verificou-se que a implantação dos grandes projetos na Amazônia amapaense vem intensificando a explosão demográfi-

\footnotetext{
${ }^{2} 0$ capital-natural é representado pelo conjunto dos recursos biológicos em sua diversidade e é visto neste trabalho como a possibilidade de gerar lucros, sem destruir as florestas ou utilizando-as de forma racional.
} 
ca nos núcleos urbanos das regiões impactadas, principalmente em Ferreira Gomes e Porto Grande. Exemplos da ausência de planejamento não faltam no estado do Amapá, que só surgem após os impactos dos grandes projetos que atraem para os territórios dos municípios, diversos trabalhadores em busca de empregos - que no primeiro momento, quando são incorporados, viabilizam a obra de exploração, mas em um segundo momento, ficam à margem da sociedade, em atividades de subemprego ou mesmo desempregados, em alguns casos, aumentando os índices de criminalidade.

Esta pesquisa também se faz necessária devido à importância do incremento da produção bibliográfica sobre a temática proposta. Os dados levantados por certo contribuirão para a elaboração de artigos em revistas, livros e trabalhos em eventos e, consequentemente, para 0 aumento da produção científica sobre o uso dos recursos naturais na Amazônia amapaense. Neste sentido, torna-se importante pesquisar sobre o assunto, uma vez que impactos negativos podem ser sentidos pelas comunidades próximas como dos municípios de Porto Grande e Ferreira Gomes, além da capital amapaense, no que diz respeito a acidentes de trabalho, vazamentos de combustíveis, alagamentos, como noticiado pela imprensa em 2015 (G1 NOTíCIAS, 2015a, 2015b), além de outros riscos ambientais que se mostram de forma nociva para a saúde das pessoas.

\section{USO DO TERRITÓRIO E A CONSTRUÇÃO DE UHE NA BACIA DO RIO ARAGUARI}

A implantação de grandes projetos, como aqueles voltados à questão mineral, em muito, está associada aos problemas ambientais na Amazônia, envolvendo grupos ambientalistas que - no intuito de conservar os recursos naturais - cada vez mais se organizam no campo social. Também, pode-se perceber a maior presença do Estado na elaboração de políticas voltadas ao planejamento ambiental regional. É no desenrolar dos processos econômicos no espaço amazônico que os atores sociais aparecem contribuindo com grande parcela para as novas relações socioambientais que se implantam na região amapaense (PALHETA DA SILVA, 2013).

Nos últimos anos, na região amazônica, a intensificação da criação de áreas especiais tem gerado discussões polêmicas, pois sua criação implica a constituição de uma série de regras e normas que são estabelecidas para o uso racional dos recursos. A criação de Terras Indígenas, Quilombolas e as Unidades de Conservação na região amazônica se tornaram instrumentos de gestão territorial significante, uma vez que 0 combate ao desmatamento tem se mostrado como de fundamental importância para a preservação dos estoques biológicos existentes na região.

$\mathrm{Na}$ figura 01 percebe-se a localização das áreas especiais criadas no Estado do Amapá nos últimos anos. 0 surgimento da maioria deu-se em locais estratégicos, segundo as especificidades de cada território, onde tem-se 0 interesse de manter os estoques naturais por tempo indeterminado, conforme as determinações de seus decretos de criação. A distribuição das áreas especiais no estado do Amapá demons- 
tra espaços onde existem mais áreas especiais e outras onde estas são inexistentes. Este fator está diretamente ligado ao nível de antropismo da região e sua representatividade quanto à questão ambiental nos âmbitos regional, nacional e internacional.

Figura 1: Áreas Especiais no Amapá

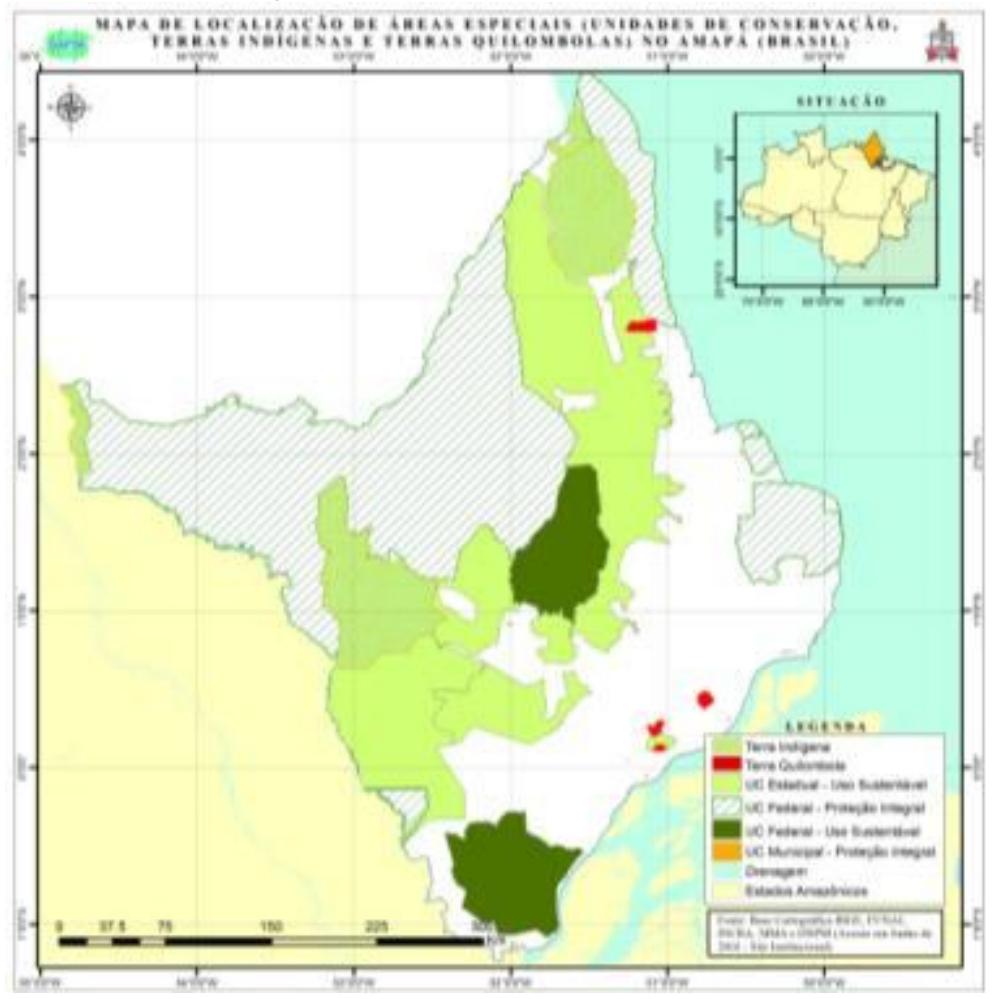

Fonte: Elaborado pelos Autores.

Nesse sentido, desde já, é importante perceber que o Amapá possui em seu território uma rica sociobiodiversidade (GOM ES, 1999; COUTINHO e PIRES, 1997) - como se percebe na figura 1 - que sempre atraiu várias empresas que realizam o beneficiamento de minérios ou empreendimentos de UHE planejadas e implantadas para atender esses projetos de mineração, que fazem com que 0 Amapá tenha a capacidade de conectar o local à economia internacional (CHAGAS, 2015; CHELALA, 2011), reorganizando o espaço geográfico e provocando, no território, complexidades diferenciadas, articulando relações que fogem à escala local e produzem novas territorialidades a partir da dinâmica econômica das grandes empresas.

A Amazônia amapaense participa diretamente deste cenário por apresentar diversas vantagens competitivas, que reduziriam os custos produtivos do modelo de acumulação capitalista cujo interesse é aproveitar as vantagens e benefícios socioambientais dessa região, com destaque para a diversidade de tipos de minérios encontrados, como manganês, ouro, bauxita, caulim, ferro, entre outros. (Figura 2). 
Figura 2: Atividades M inerárias no Amapá, com destaque para a Bacia do Rio Araguari

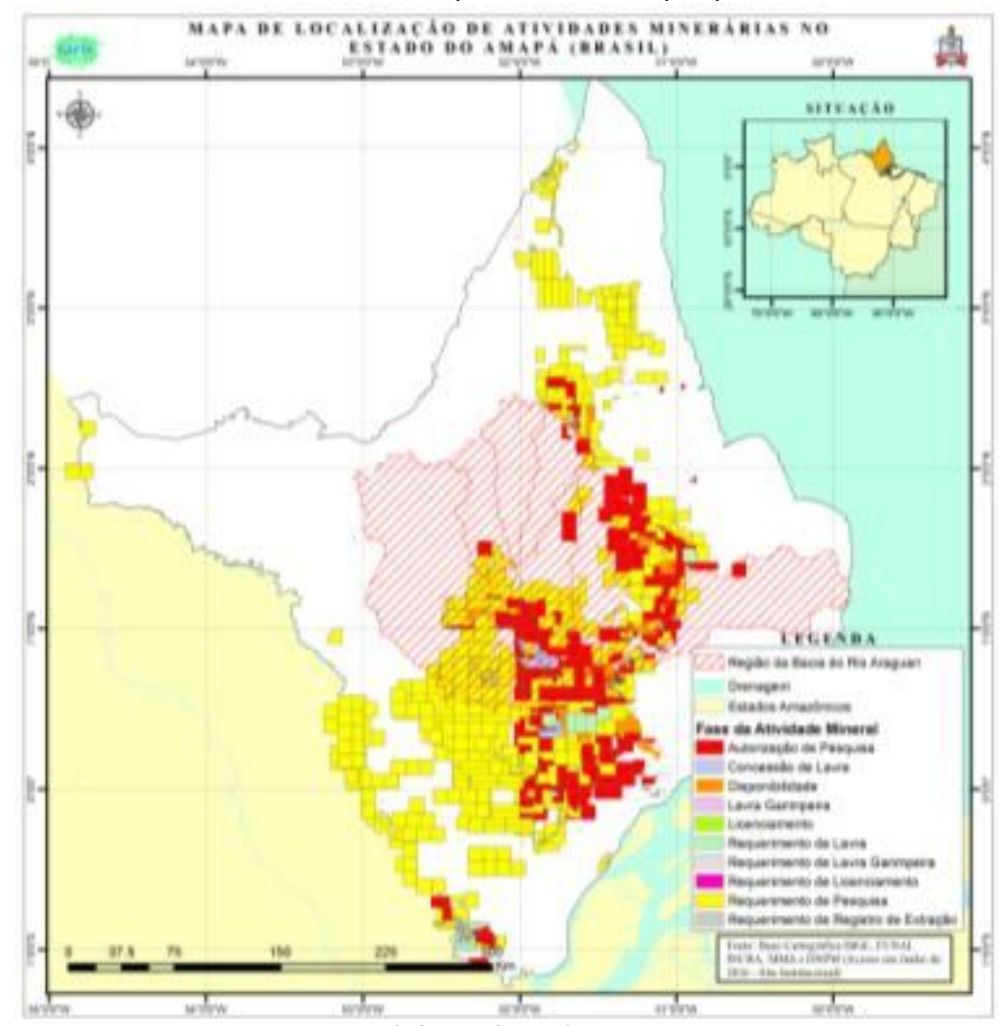

Fonte: Elaborado pelos Autores.

Ao analisar as figuras 1 e 2 percebe-se que há uma sobreposição de atividades conflitantes no território, cujo Estado aparece como principal articulador das formas de usos e de regulação destes espaços.

O potencial hidroelétrico no Amapá é um dos recursos que mais destacam este estado, pois, a geração de energia aliada aos interesses do capital nacional e internacional imprimem a este território uma posição estratégica. Neste sentido, os estudos para a construção da UHE de Coaracy Nunes, iniciaram ainda na década de 1950, todavia, somente no final da década de 1960 os estudos sobre a viabilidade para a construção da hidroelétrica foram finalizados, por meio da assinatura do contrato entre o Governo do Território Federal do Amapá (GTFA) e a empresa TECHINT, uma empresa de M ilão (Itália), fundada em 1945. De acordo com a CEA (2016), a Companhia Brasileira de Engenharia executou o estudo para a geração de uma potência de $100.000 \mathrm{KW}$, sendo 08 unidades de $12.500 \mathrm{KW}$ cada.

Ainda,

A primeira disposição de ordem legal relacionada com o problema de energia elétrica no Amapá é constituída pelo Decreto 35.701 de 23 de junho de 1954, atribuindo ao Governo do Território do Amapá (GTFA) a incumbência de promover 0 aproveitamento progressivo da energia hidráulica da Cachoeira de Paredão (...) Neste ano o GTFA contratou os serviços aerofotogramétricos e a firma SERVIX ENGENHARIA para executar o anteprojeto para 
uma potência de $46.600 \mathrm{KW}$ com duas unidades de $23.300 \mathrm{KW}$ cada.

Posteriormente, a Lei ${ }^{\circ} 2.740$ de 02 de março de 1956 autorizou o governo a criar a COM PANHIA DE ELETRICIDADE DO AM APÁ - CEA, com o objetivo de construir e explorar os sistemas de produção, transmissão e distribuição de energia no Território Federal, visando basicamente promover as medidas necessárias para a expansão do mercado de energia elétrica, prevendo e estimulando a criação de um parque industrial.

A CEA iniciou os estudos aerofotogramétricos, topográficos, hidrológicos, e desmatamento da área. Em 1959, já dispondo dos levantamentos topográficos da bacia de acumulação, levantamento batimétricos, sondagens dos eixos das barragens e outros estudos, a CEA abriu concorrência pública para definir a execução do projeto, que previa uma potência de $180.000 \mathrm{KW}$, com cinco unidades geradoras de 36.000 KW (CEA, 2016).

Percebe-se, portanto - que na sua gênese - a estruturação do setor elétrico no Amapá já nasce estatal e federalizado, destoando, de certa maneira, do caminho percorrido em outras regiões ${ }^{3}$. Em 1974, a ELETRONORTE implanta a sua regional do Amapá, cujo principal objetivo foi concluir as obras da usina Coaracy Nunes, inaugurada em janeiro de 1976. Esta usina foi a primeira hidroelétrica construída pela ELETRONORTE em toda a Amazônia, se constituindo em um marco inicial do que seria a atuação da empresa nas décadas seguintes por meio dos seus diversos planos de ação.

De acordo com Rocha ${ }^{4}$ (2008) a geração de energia elétrica no Brasil passou por várias fases nas últimas décadas, a saber: Intervenção do Estado na economia (19501960); expansão do Estado na geração e na transmissão de energia elétrica (1960) e 0 início da federalização do setor (1970). Nesses últimos anos, o arranjo institucional e os investimentos no setor elétrico brasileiro foram relevantes instrumentos de geopolítica para o controle do território Amazônico, iniciado durante a ditadura militar, por meio da criação da ELETROBRÁS e suas subsidiárias, como a Centrais Elétricas do Norte do Brasil (ELETRONORTE) em 1973.

Desse modo, a justificativa para a instalação da ELETRONORTE no Amapá teve como principal discurso a necessidade da conclusão das obras da Usina Hidrelétrica Coaracy Nunes, no Rio Araguari (ELETRONORTE, 2015). No que concerne às fases do setor elétrico, a construção da UHE Coaracy Nunes corresponde às fases iniciais do desenvolvimento do setor elétrico no Brasil, da intervenção do Estado na economia (1950-1960), ao início da federalização do setor (1970).

Nota-se assim - como aconteceu no estado do Pará e em outros estados - que a geração de eletricidade voltou-se para atender os grandes projetos e não a sociedade

\footnotetext{
${ }^{3}$ Em junho de 2013, iniciou-se um novo processo de federalização da CEA, que estava falida e com débitos junto à Eletronorte, ficando a federalização como alternativa apontada para impedir a caducidade da empresa.

${ }^{4} \mathrm{O}$ Dr. Gilberto Rocha descreve de maneira detalhada a formação e a dinâmica do setor elétrico brasileiro, dando destaque para a ELETROBRAS, suas subsidiárias e processo e implantação da Usina Hidrelétrica de Tucuruí.
} 
amapaense o que, de certa maneira, refletiu diretamente nos impactos que atingiram as populações a montante e a jusante das obras das UHE, tanto com a desterritorialização de comunidades que existiam, quanto com o alagamento das margens dos rios que também foram impactados. Estes fatos desmobilizaram e desterritorializaram todo um contingente populacional local que tinha seu modo de vida atrelado aos costumes locais e que, com a construção das obras das UHE, foram direcionados como mão de obra, concorrendo com um contingente populacional imigrante que fluiu para os municípios próximos aos grandes empreendimentos. Nos dias de hoje, esse princípio continua, pois novas empresas foram instaladas e novos projetos (minerometalúrgicos e hidroelétricos) estão sendo executados, como será apresentado a seguir.

\subsection{As UHE Ferreira Gomes e Cachoeira Caldeirão}

A crescente comercialização do aço no mercado mundial recoloca o Amapá no cenário da mineração de ferro, visando a produção de seus derivados metálicos como 0 ferro gusa e o ferro esponja. 0 que foi verificado, principalmente, a partir de 2004, com a criação do projeto minerometalúrgico da empresa Mineração e Metalurgia Ltda. (MMX), que previu a construção de um complexo logístico para exportação de minério. 0 projeto da $M M X$ contava com a operação de uma mina com planta de ferro-gusa para a exploração de 6,5 milhões de toneladas/ano, cuja previsão de início foi o segundo semestre de 2007, além da edificação de uma estrada de ferro de 198 quilômetros para o transporte de 2 milhões de toneladas anuais, a partir de abril de 2008 e pelo Terminal Portuário de Santana.

O planejamento da produção mineral conta que parte do minério de alto teor agregado (acima de 67\%), 500 mil toneladas, serão destinadas à produção de semiacabados e o restante (1,5 milhão de toneladas) à exportação. Este novo momento de mineração empresarial no Amapá seguiu o padrão de enclave (Mineração+Siderurgia), com uso intensivo de capital, tecnologia e energia com baixa geração de empregos especializados.

Porém, o crescimento da demanda de ferro pelos mercados mundiais tornou atrativa a retomada da atividade mineral, visto que, em 2004, somente a China demandou um quarto (1/4) do aço produzido no planeta, superando EUA e o Japão, o que aumentou a pressão sobre as mineradoras na escala mundial. 0 estado do Amapá participa desse comércio mundial de minérios com uma parcela considerável de sua produção mineral (PALHETA DA SILVA, 2013).

Todavia, Monteiro (2016) chama a atenção para o modelo siderúrgico na Amazônia que é baseado em estruturas arcaicas, no latifúndio que transforma a floresta em carvão para a produção do ferro. Segundo o autor, no ano de 2003 para a produção de 2,2 milhões de toneladas de ferro gusa, se queimou 5,7 milhões de toneladas de madeira. Neste sentido, seria a destruição da floresta o motivo pelo qual alguns seto- 
res empresariais e outros ambientalistas estariam tão favoráreis à proliferação de hidroelétricas na Amazônia?

De acordo com Chagas (2015), é só a partir da segunda metade da década de 1990, com a retomada do crescimento econômico brasileiro e o consequente consumo de energia, que o Governo brasileiro atenta para a carência de energia e propõe a construção de novas hidrelétricas na Amazônia, (re) potencialização de usinas antigas (o caso de Coaracy Nunes), além de interligar a geração de energia na Amazônia ao sistema nacional e aos sistemas isolados, atendendo assim a demanda crescente das indústrias.

Ainda de acordo com Chagas (2015), existem dois inventários hidrelétricos realizados no Amapá e aprovados pela ANEEL 5 .

O primeiro foi desenvolvido na década de 1990 pela Eletronorte em conjunto com a empresa Hydros Engenharia. 0 estudo abrangeu as bacias dos rios Araguari, Calçoene, Cassiporé, Tartarugal Grande, Tartarugalzinho, Amapá Grande. Este inventário foi o primeiro passo para que ocorresse o leilão das hidrelétricas Ferreira Gomes e Cachoeira Caldeirão, no Rio Araguari (CHAGAS, 2015, s/p).

A partir da análise destes inventários se delineia a implantação das usinas hidrelétricas Ferreira Gomes e Cachoeira Caldeirão. Tais usinas fazem parte do segundo Programa de Aceleração do Crescimento (PAC-2) e foram leiloadas pela ANEEL com preço final de $\mathrm{R} \$ 69,78 / \mathrm{M}$ Wh e R\$ 95,31/M Wh, respectivamente, que são valores abaixo das expectativas do mercado cujo preço final orbitava em torno de $\mathrm{R} \$ 100 / \mathrm{MWh}^{6}$. Contudo, torna-se importante enfatizar que a bacia do rio Araguari abrange diversas atividades minerais e áreas especiais no Amapá - como visto nas figuras 1 e 2 - e a construção de UHE nessa região impactará com intensidade os recursos naturais e os habitantes da região (Figura 3).

${ }^{5}$ Chagas (2015) informa que o segundo estudo de inventário é da bacia do rio Jari, finalizado em 2010 pela Hydros Engenharia, contratada pela Empresa de Pesquisa Energética (EPE) para esta finalidade.

${ }^{6}$ As condições de uso foram estabelecidas nos contratos 02/2010 e 01/2013 celebrados entre o MME e as concessionárias vencedoras do leilão das hidrelétricas. 
Figura 3: Localização das áreas Especiais no Amapá, com destaque para a Bacia do Rio Araguari

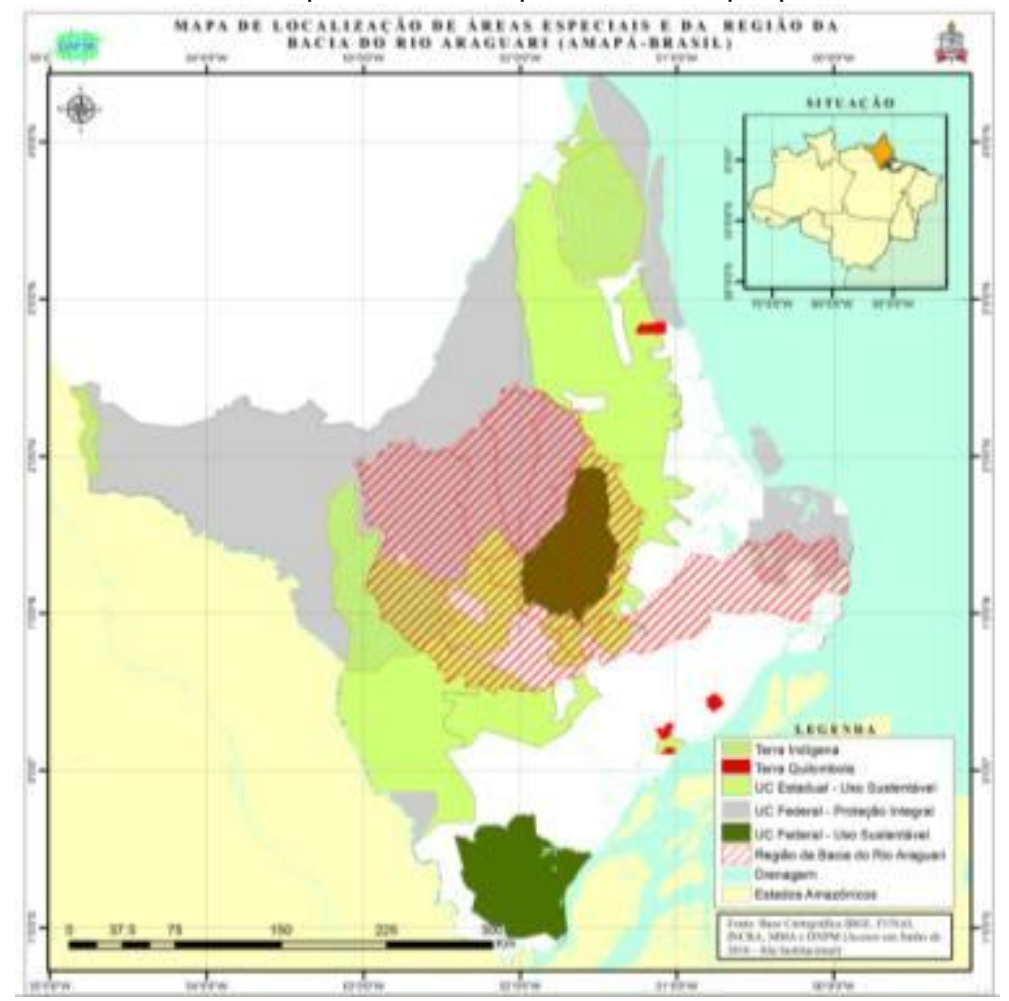

Fonte: Elaborado pelos Autores.

De acordo com dados da Eletrobrás/Eletronorte, o Estado contava apenas com a hidrelétrica de Coaracy Nunes e a Termelétrica de Santana. Juntas, as usinas dispõem de 256,1 MW de potência, o que não corresponde a toda demanda do Amapá. Uma das reclamações da população macapaense são as quedas de energia, principalmente no período do verão, onde o nível do rio diminui. A previsão para os próximos anos é que o Estado seja beneficiado com a construção de novos empreendimentos.

Para o presidente da Companhia de Eletricidade do Amapá (CEA), José Ramalho:

As obras estão aceleradas e a previsão da Ferreira Gomes energia é que no fim do ano que vem o estado já seja beneficiando com 252 MW e mais 370 MW, da hidrelétrica de São José. Em breve teremos mais a hidrelétrica de Cachoeira Caldeirão, o que nos levará a uma produção 15 vezes maior do que a atual de energia (PORTAL AM AZÔNIA, 2012).

O site Portal da Amazônia que entrevistou José Ramalho obteve a informação de que a possibilidade do aumento da geração de energia é prevista para os próximos anos, em que:

Com obras em andamento, o Amapá prepara-se para ser um dos grandes produtores de energia do Brasil. Três novas hidrelétricas, a Ferreira Gomes Energia, Hidrelétrica de Santo Antônio do Jari, e a mais recente, Cachoeira Caldeirão, entrarão em operação no Estado. Para somar a essas constru- 
ções, o governo federal investe na ampliação da Hidrelétrica de Coaracy Nunes. Juntas, elas produzirão 15 vezes mais do que é produzido atualmente. 0 investimento em energia no Estado vai contribuir para o desligamento de algumas usinas poluidoras que usam óleo diesel. Atualmente este tipo de tecnologia ainda atende a $80 \%$ da demanda do Amapá (PORTAL AMAZÔNIA, 2012).

Desde a publicação desta citação até a atualidade (2016), o que se vê é que este planejamento está sendo, aos poucos, executado, visto o aumento crescente da demanda nos últimos anos e a chamada "crise energética" prevista para atingir o Brasil nos próximos anos e que foi enfatizada pela escassez hídrica em 2015 no estado de São Paulo, que mostrou a vulnerabilidade do estado brasileiro com maior população frente à escassez de água e energia elétrica.

É irrefutável que o Brasil tem uma demanda crescente por energia. 0 retorno ao uso de termoelétricas pelo Governo brasileiro mostra a fragilidade do setor primário de geração de energia. A região amazônica, mais uma vez, se mostra como uma fornecedora de matéria-prima ao capital. Só resta observar se ocorrerão retornos benéficos aos habitantes da região ou se apenas herdarão os impactos negativos gerados pela instalação e a operação destes empreendimentos.

No Amapá a geração de energia é um dos diversos potenciais latentes na região. A carência por energia dos últimos anos colocou o estado junto com outros: Pará e Rondônia, principalmente, onde a construção de hidroelétricas é possível. A figura 4 mostra o planejamento governamental em ação para a construção de UHE no estado do Amapá, com enfoque para a bacia do rio Araguari, tema principal deste manuscrito.

É possível verificar na figura 4 o planejamento governamental-territorial previsto para a bacia do rio Araguari que impacta e/ou impactará as cidades próximas, seja com a construção de infraestrutura ou com os impactos ambientais advindos com as obras e com a operação da UHE. 
Figura 4: Fonte Hídrica - Geração de Energia Elétrica: Estado do Amapá

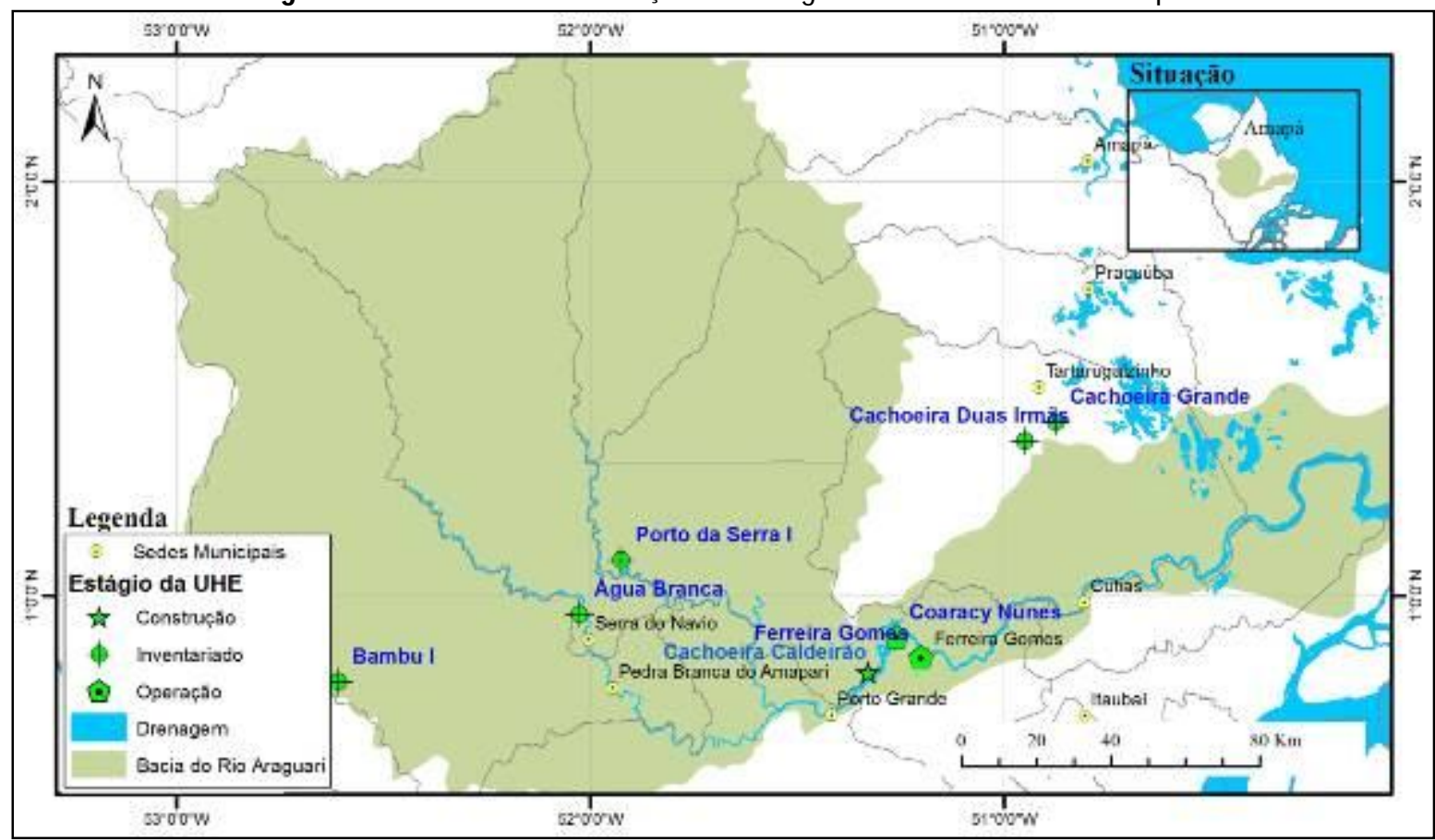

Fonte: Dados extraídos de Brasil (2011) e de Pesquisa em Campo (2016).

A Usina Hidrelétrica de Cachoeira Caldeirão, situada a montante da UHE Coaracy Nunes, com potência de $219 \mathrm{MW}$ (equivalente a atual demanda total do Amapá), tem um reservatório de $47,9 \mathrm{Km}^{2}$, cuja metade já corresponde à calha atual do rio Araguari. Chelala (2011) ressalta que o planejamento desta UHE pretende operar em regime de fio d'água, o que significa que não armazenará água e pouco influenciará no regime normal do rio, além de reduzir a área alagada, isto é, o objetivo de reduzir a área de impacto direto pode acarretar em menores perdas ambientais para a região do entorno. A figura 5 localiza as UHE Ferreira Gomes, Coaracy Nunes e Cachoeira Caldeirão e mostra as áreas previstas para serem diretamente impactadas por estes empreendimentos. 
Figura 5: Áreas de Influência das UHE Ferreira Gomes, Coaracy Nunes e Cachoeira Caldeirão, Estado do Amapá

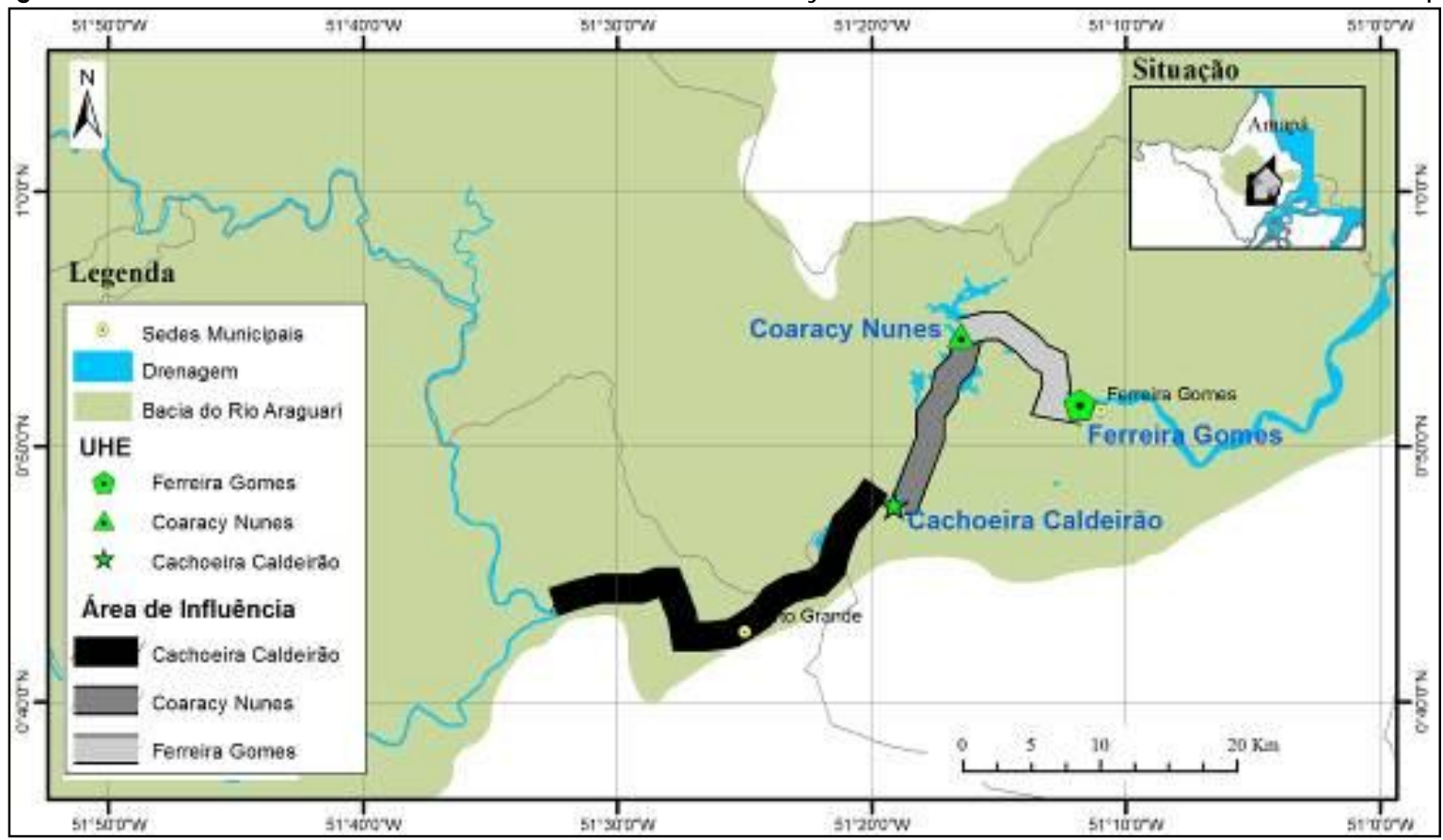

Fonte: Baseado em ElA (2013) e Pesquisa em Campo (2016).

0 investimento é estimado em $\mathrm{R} \$ 1,4$ bilhão e deverá gerar 2 mil empregos diretos e 6 mil indiretos. A elaboração do Plano Básico Ambiental do Aproveitamento Hidrelétrico Cachoeira Caldeirão (PBA, 2013) conta com pesquisadores de diversas áreas que procuraram mostrar os reflexos da instalação da UHE, porém, é possível verificar que os impactos causados pela migração de operários ou trabalhadores indiretos é evidenciado neste documento, conforme se vê na citação abaixo:

A instalação da UHE Cachoeira Caldeirão pode oportunizar aos municípios da AID, principalmente aos núcleos urbanos, a dinamização da economia e o fortalecimento do poder municipal com 0 aumento da arrecadação de impostos. Essa oportunidade é fruto dos investimentos diretos e indiretos vinculados ao empreendimento, da execução de programas de fomento em setores importantes da economia como valorização de fornecedores, agricultura e pesca, mas também do incremento populacional decorrente.

Este crescimento da população, quando desordenado, causa transtornos sociais graves, comuns em locais onde se instalam empreendimentos de grande porte. Por outro lado, quando planejado e orientado por políticas e programas sociais, promove 0 aumento do mercado interno, maior circulação de recursos financeiros, amplia as possibilidades de geração de renda e pode impulsionar o desenvolvimento local. É sob essa perspectiva que os Programas de Apoio à Infraestrutura Social e Produtiva dos Municípios de Porto Grande e Ferreira Gomes (assistência social, saúde, educação, habitação e segurança pública) do PBA do AHE Cachoeira Caldeirão foram elaborados (PBA, 2013, p. 14). 
Ademais, a História mostra que esse tipo de empreendimento causa impactos radicais na estrutura política, econômica e ambiental dos municípios atingidos diretamente. Rocha (2008) observou que após a construção da UHE de Tucuruí todo o território atingido sofreu alteração, com um contingente migrante significativo que não encontrou serviços básicos para o seu atendimento, o que gerou problemas sérios ambientais e sociais - para toda região. Um dos efeitos iniciais sentidos em Tucuruí foi a fragmentação territorial que ocorreu, com a criação de outros municípios, instituições e serviços, que geraram uma nova dinâmica regional, o que também ocorre com a criação de empreendimentos minero-metalúrgicos, que intensificam a ocupação territorial onde são instalados (PALHETA DA SILVA, 2013).

Esse fato é enfatizado no próprio PBA, em que Alegretti informa que,

A migração populacional espontânea para locais onde existem obras de infraestrutura em implantação tem sido recorrente na Amazônia nas últimas décadas. Estradas, hidrelétricas, projetos de exploração mineral, abertura de zonas de livre comércio, entre outros, são exemplos clássicos de atração populacional em volume maior do que uma obra ou projeto comportam, dando origem a bairros periféricos com população marginalizada. Sem qualificação e sem oportunidade de se inserir no mercado formal de trabalho, esses grupos sociais não geram renda e ficam vulneráveis e dependentes das políticas de assistência social das prefeituras. (ALLEGRETTI, apud PBA, 2013, p. 15).

M unicípios com estrutura simples, com carência de infraestrutura e pouca dinâmica econômica, Porto Grande e Ferreira Gomes, que compõem a Área de Influência Direta (AID), serão os municípios mais atingidos pela operação das UHE de Ferreira Gomes e Cachoeira Caldeirão. O Plano Básico Ambiental do Aproveitamento Hidrelétrico Cachoeira Caldeirão (PBA, 2013) aponta fatores negativos que podem ocorrer com a instalação de UHE na região, mas também procura mitigar estes impactos com a possibilidade de geração de emprego e renda, além da absorção da mão de obra local desempregada da região e outros benefícios (educação, saúde, segurança, etc.), que podem ser alcançados com a operação da UHE.

Entretanto, os impactos causados pela abertura das comportas da UHE Cachoeira Caldeirão impactam diretamente na elevação do rio Araguari e já puderam ser sentidos no ano de 2015 , onde a cheia do rio atingiu 5,5 metros. Isto corresponde a 2,3 metros acima do considerado normal para a região e atingiu cerca de 1,4 mil pessoas, e ocorreu após abertura da barragem (G1 NOTíCIAS, 2015a; 2015b). Durante esse evento ruas foram alagadas e muitas famílias sentiram o efeito direto do que é morar nas proximidades de uma UHE (figura 6). 


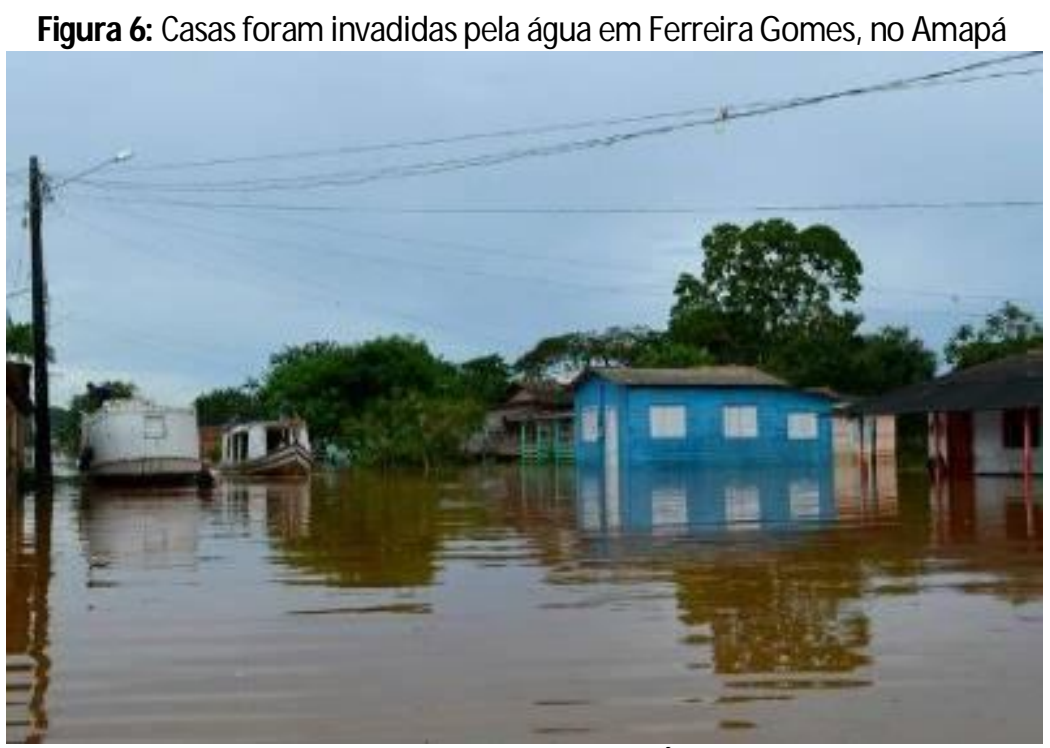

Fonte: Abinoan Santiago (G1 NOTICIAS, 2005b).

As autoridades municipais declararam situação de emergência, porém, é certo dizer que esses municípios não estão preparados para eventos extremos (inundações ou alagamentos) e/ ou erros humanos, que danifiquem mecanismos ou que repercutam na abertura incorreta das comportas e que podem refletir diretamente em situações de perda de vidas. Da mesma forma, os organismos estaduais e federais presentes nesses municípios não estão aparelhados para atender as populações atingidas por qualquer evento de desastre causado por um erro ou falha na UHE. Então, a sociedade civil organizada pode requerer mecanismos de controle e monitoramento eficientes para a prevenção ou combate a eventos de risco e/ ou ameaça.

Ainda há suspeita de responsabilidade por dano ambiental causado à ictiofauna local. 0 laudo emitido pelo Instituto de M eio Ambiente e Ordenamento Territorial do Amapá (IM AP) descartou a hipótese de poluição do rio no caso de mortandade excessiva de peixes no rio Araguari desde 2014, o laudo relata que os peixes apresentavam alterações físicas, como bolhas embaixo da pele e olhos sobressaltados, o que gera indícios de embolia gasosa provocada pela supersaturação da água liberada pelo vertedouro da usina de Cachoeira Caldeirão (GEA, 2016).

O Laudo de Engenharia Legal revela que, em qualquer caso, "não há Plano de Ação Emergencial (PAE) conjunto (...) entre as barragens em operação UHE de Coaracy Nunes e UHE Ferreira Gomes, em construção, UHE - Cachoeira Caldeirão" (GEA, 2015). Todavia, há de se compartilhar a responsabilidade de dano ambiental, pois, trata-se de um processo em cadeia, pois existe um conjunto de usinas operando no rio.

De acordo com a empresa Ferreira Gomes Geração de Energia (2015), a Usina Hidrelétrica (UHE) Ferreira Gomes terá capacidade de gerar $252 \mathrm{M}$ wh de energia elétrica e 149,16 de energia firme, o suficiente para atender a uma cidade de cerca de 700 mil habitantes. Esta hidrelétrica também está na bacia do rio Araguari, com uma vazão de $938 \mathrm{~m}^{3} / \mathrm{s}$, com uma área a ser alagada de $17,7 \mathrm{~km}^{2}$ e uma queda d'água de 
18,04 metros, encontra-se em funcionamento desde 2015 (FERREIRA GOM ES GERAÇÃO DE ENERGIA, 2015) (figura 7).

Figura 7: Barragem, vertedouro e casa de Força da UHE - Ferreira Gomes, no Amapá

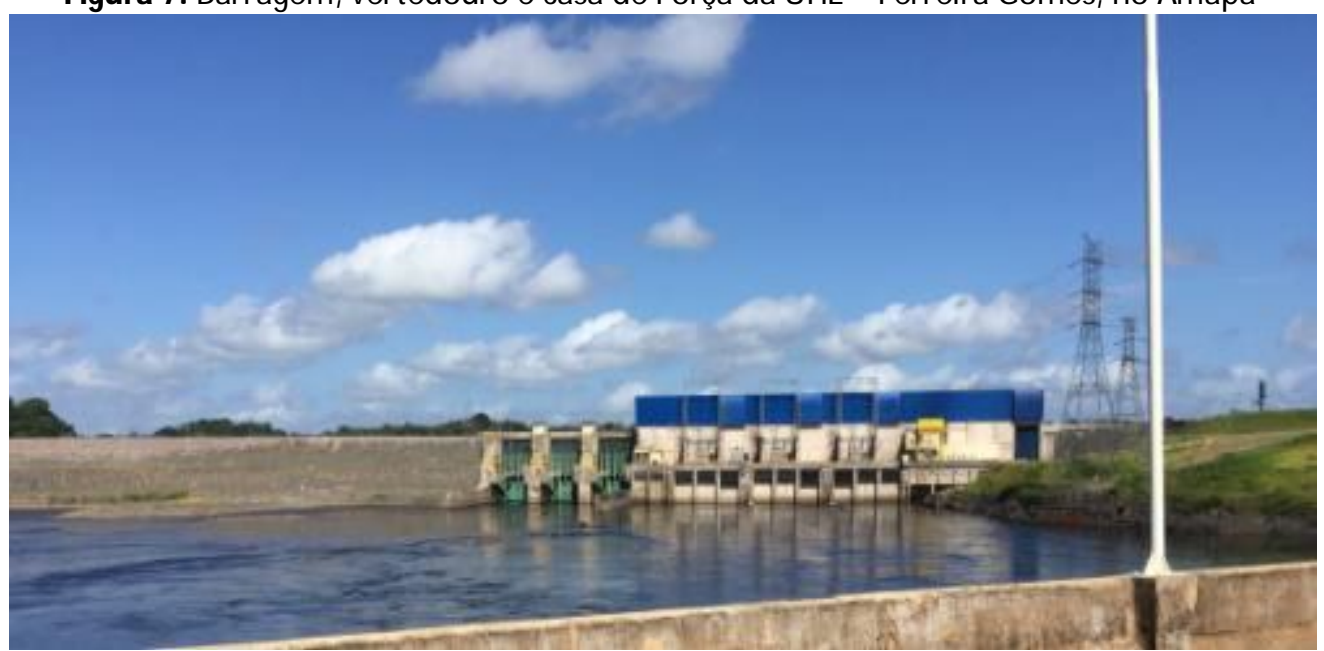

Fonte: Ricardo Lima (Pesquisa de campo, 2016).

Apesar de possuir Licença de Operação, desde 2014, a Ferreira Gomes S/A não possui um plano emergencial para inundações ou para controlar a mortandade de peixes devido à operação das comportas. Por este motivo, a hidrelétrica se encontra questionada sobre a sua responsabilidade nos eventos ambientais na bacia do rio Araguari.

A Ferreira Gomes Energia, (...) disse que na noite de 7 de maio de 2015, a enchente que atingiu parte da cidade de Ferreira Gomes foi provocada pela Cachoeira Caldeirão, hidrelétrica que está sendo construída pela EDP na região. Segundo a empresa, um volume de água do rio foi liberado pela Cachoeira Caldeirão sem que houvesse comunicação às demais hidrelétricas instaladas no Araguari: a Ferreira Gomes Energia e a Coaracy Nunes. A EDP disse que comunicou a abertura de uma ensecadeira às empresas. De acordo com a prefeitura, mais de 600 pessoas foram atingidas pela cheia. A cidade está em situação de emergência (G1 NOTÍCIAS, 2005b).

Tudo indica que nenhuma das empresas assume a sua parcela de responsabilidade nos sucessivos, sinistros, acontecimentos no rio Araguari após o início da construção e operação das novas hidrelétricas. Acrescenta-se a excessiva mortandade de peixes no rio, impactando diretamente a atividade de pesca em Ferreira Gomes ${ }^{7}$. Essas ocorrências se tornaram objeto da Ação Civil Pública 01627-41.2015, impetrada pelo Ministério Público em desfavor da Ferreira Gomes Energia S/A, pelo motivo Dano ao M eio Ambiente, cujos desdobramentos ainda se encontram em andamento.

\footnotetext{
${ }^{7}$ Em períodos de 28-31/07/2014, 30/08-04/09/2014, 04/10/2014, 13/11/2015, 19/01/2016 e 24/01/2016 foram registradas mortandades de peixes por pescadores artesanais de Ferreira Gomes.
} 


\section{CONSIDERAÇÕES FINAIS}

A utilização dos recursos naturais pela sociedade vem se demonstrando como uma forma irracional, pois, o manejo negativo é notado em todas as áreas que não se propõem à preservação e/ ou conservação de tais recursos. Os desafios e possibilidades de um uso sustentável dos recursos naturais aliados ao crescimento/desenvolvimento econômico devem se constituir numa reflexão permanente, que oriente a implementação das políticas públicas, mas também atenda aos anseios e reivindicações da sociedade local. Destarte, deve se considerar a Amazônia como importante para o Brasil e o mundo, uma região prioritária articulando desenvolvimento econômico ao desenvolvimento cultural das populações residentes e não somente para exploração enquanto almoxarifado de riquezas, como vem ocorrendo durante todos os contextos históricos em que a Amazônia é citada na literatura, cientifica ou não.

A implantação dos grandes projetos na Amazônia intensificou a explosão demográfica dos diversos núcleos urbanos nas regiões impactadas. Exemplos da ausência de planejamento não faltam no estado do Amapá, que só surgem após os impactos dos Grandes Projetos que atraem para os territórios dos municípios diversos trabalhadores em busca de empregos - que no primeiro momento, quando são incorporados, viabilizam a obra de exploração, mas em um segundo momento, ficam à margem da sociedade, em atividades de subemprego ou mesmo desempregados, em alguns casos, aumentando os índices de criminalidade.

0 relatório de Tourinho et al. (1991) fornece elementos para pensar a desestruturação e reestruturação socioespacial em um município impactado por um grande projeto (como ocorreu em Barcarena, no estado do Pará), mostrando que não se pode apenas compreender a estruturação espacial do grande projeto, mas também a (des) reestruturação dos demais espaços impactados, em decorrência das desapropriações necessárias para a efetivação do projeto e da ausência de oportunidades para uma parcela significativa da população. É importante destacar que, geralmente, a representação social é colocada à margem das decisões referentes à implantação do projeto, às desapropriações e aos assentamentos que são criados a montante e a jusante. Tal exclusão é justificada pelo Governo Federal como resultado da ineficiência administrativa do município.

Estima-se que cerca de 600 famílias foram atingidas diretamente pelas barragens citadas neste artigo. De acordo com o Tribunal de Justiça do Amapá, em 2015, foram pagas indenizações prévias de $\mathrm{R} \$ 20.000,00$ por danos materiais para residentes e de $\mathrm{R} \$ 35.000,00$ para comerciantes ou estabelecimentos mistos, somando quase 400 famílias cadastradas pela Defesa Civil. Todavia, ainda há um volume de mais de 700 ações no Fórum de Ferreira Gomes, que devem aguardar a finalização da Ação Civil Pública movida pelo M inistério Público. Também, espera-se o desdobramento para 0 setor pesqueiro do município, diretamente atingido pela mortandade excessiva de peixes. É urgente o desenvolvimento de Plano Integrado de Gestão e Previsão de De- 
sastre das usinas hidrelétricas do rio Araguari, para evitar futuros danos ao meio ambiente e à sociedade local.

Apesar dos esforços locais é necessário um debate ampliado sobre a força dos agentes responsáveis pela gestão e organização dos espaços no rio Araguari, por uma margem, sujeitos à regulação do mercado de energia, e por outra margem, a forte presença da União Federal na desconstrução dos espaços locais. Percebe-se, portanto, uma real federalização na gestão do território do rio Araguari, através da Eletronorte, ANEEL, Operador Nacional do Sistema Elétrico e CEA (agora federalizada), a reconfiguração mais moderna desta geopolítica regional, ou seja, a sinergia direta entre Estado e Empresa Privada.

\section{REFERÊNCIAS}

BRASIL. M inistério do Planejamento, Orçamento e Gestão. Plano plurianual 20122015: Projeto de Lei. Brasília: M inistério do Planejamento, Orçamento e Gestão, Secretaria de Planejamento e Investimentos Estratégicos, 2011.

CASTELLS, M . 0 poder da identidade - A era da informação: economia, sociedade e cultura. São Paulo: Paz e Terra, 2001.

CHAGAS, M. Hidrelétricas no Amapá. Macapá. Disponível em: বhttp://www.alcile necavalcante.com.br/alcilene/hidreletricas-no-amapa>. Acesso em: 4 ago. 2015.

CHELALA, C. 0 Amapá e as Hidrelétricas. Macapá: Amapá, 2011. Disponível em: বhttp: //www.alcilenecavalcante.com.br/alcilene/o-amapa-e-as-hidreletricas $>$. Acesso em: 3 ago. 2015.

CEA, Companhia de Eletricidade do Amapá. Histórico. Disponível em: বttp://www. cea.ap.gov.br/area. php?id=229\&dm=277>. Acesso em: 26 fev. 2016.

COUTINHO, S. da C.; PIRES, M. J. P. Jari: um banco genético para o futuro. Rio de Janeiro: Imago, 1997.

EIA, Estudo de Impacto Ambiental. Análise ambiental das unidades de conservação afetadas pelo AHE Cachoeira Caldeirão. M acapá: Ecotumucumaque, 2013.

ELETRONORTE. Regional Amapá. Brasil: Brasília. Disponível em: «ttp://www.eln.gov. br/opencms/opencms/aEmpresa/regionais/amapa/ >. Acesso em: 29 jul. 2015.

FERREIRA GOMES GERAÇÃO DE ENERGIA. Usina. São Paulo, 2015. Disponível em: বttp://www.ferreiragomesenergia.com.br/ferreiragomes/web/conteudo_pti.asp?idi oma $=0 \&$ tipo $=40874 \&$ conta $=45>$. Acesso em: 5 ago. 2015.

FERREIRA, E. A. C. 0 mundo Contemporâneo. São Paulo: Editora Núcleo, 1986.

GEA. Imap e Sema investigam causas de morte de peixes no Rio Araguari. Macapá: IM AP, 2016. Disponível em: বhttp://www.imap.ap.gov.br/det.php?cd=3153>. Acesso em: 13 mar. 2016.

GEA. Laudo $N^{\circ}$ 49.945/2015-DC/ Politec - Laudo de exame de corpo de delito de engenharia legal. Macapá: POLITEC, 2015.

G1 NOTÍCIAS, Nível do rio Araguari em Ferreira Gomes chegou a 5,5m, diz Defesa. 
08/05/2015a. Disponível em: বhttp://g1.globo.com/ap/amapa/noticia/2015/05/nivel -do-rio-araguari-em-ferreira-gomes-chegou-55m-diz-defesa.html>. Acesso em: 8 mar. 2016

GI NOTÍCIAS, Empresa diz que cheia em Ferreira Gomes foi causada por hidrelétrica. 08/05/2015b. Disponível em: 〈http://g1.globo.com/ap/amapa/noticia/2015/05/empr esa-diz-que-cheia-em-ferreira-gomes-foi-causada-por-hidreletrica.html>. Acesso em: 8 mar. 2016

GOM ES, F. dos S. (Org.) Nas terras do Cabo Norte: fronteiras, colonização e escravidão na Guiana Brasileira (séculos XVIII-XIX). Belém: Editora Universitária/UFPA, 1999. M INISTÉRIO DAS M INAS E ENERGIA. Plano Nacional de Energia Elétrica. Rio de Janeiro: Eletrobras, 1987.

PALHETA DA SILVA, J. M. Território e mineração em Carajás. Belém: GAPTA/UFPA, 2013.

PBA, Plano Básico Ambiental do Aproveitamento Hidrelétrico Cachoeira Caldeirão. Volume III. Programas meio socioeconómico. M acapá: Ecotumucumaque, 2013. PORTAL AM AZÔNIA, Amapá exportará energia para outros estados do Brasil, diz presidente da CEA. 2012. Disponível em: বhttp://www.portalamazonia.com.br/edi toria/atualidades/amapa-exportara-energia-para-outros-estados-do-brasil-diz-presid ente-da-cea/ > Acesso em: 2 mai. 2016.

ROCHA, G. de M. Todos convergem para o lago: hidrelétrica Tucuruí, municípios e territórios na Amazônia. Belém: NUM A/UFPA, 2008.

SANTOS, L. G. dos. A encruzilhada da política ambiental brasileira. In: D'INCAO, M. (Org.) A Amazônia e a crise da modernização. Belém: M PEG, 1994. p. 135-154.

TOURINHO, H. Z. et al. (Org.) Repercussões sócio-econômicas do complexo Albrásalunorte em área de sua influência imediata. Belém: IDESP, 1991.

Artigo recebido em 02 de setembro de 2016.

Aprovado em 17 de janeiro de 2017. 